\title{
The Role of Adenine Nucleotide Translocase in the Mitochondrial Permeability Transition
}

\author{
Nickolay Brustovetsky \\ Department of Pharmacology and Toxicology, Stark Neurosciences Research Institute, \\ Indiana University School of Medicine, Indianapolis, IN 46202, USA; nbrous@iu.edu; Tel.: +317-278-9229; \\ Fax: +317-274-7714
}

Received: 30 November 2020; Accepted: 12 December 2020; Published: 15 December 2020

\begin{abstract}
The mitochondrial permeability transition, a $\mathrm{Ca}^{2+}$-induced significant increase in permeability of the inner mitochondrial membrane, plays an important role in various pathologies. The mitochondrial permeability transition is caused by induction of the permeability transition pore (PTP). Despite significant effort, the molecular composition of the PTP is not completely clear and remains an area of hot debate. The $\mathrm{Ca}^{2+}$-modified adenine nucleotide translocase (ANT) and $\mathrm{F}_{0} \mathrm{~F}_{1}$ ATP synthase are the major contenders for the role of pore in the PTP. This paper briefly overviews experimental results focusing on the role of ANT in the mitochondrial permeability transition and proposes that multiple molecular entities might be responsible for the conductance pathway of the PTP. Consequently, the term PTP cannot be applied to a single specific protein such as ANT or a protein complex such as $\mathrm{F}_{0} \mathrm{~F}_{1}$ ATP synthase, but rather should comprise a variety of potential contributors to increased permeability of the inner mitochondrial membrane.
\end{abstract}

Keywords: calcium; permeability transition pore; adenine nucleotide translocase; cyclophilin D; $\mathrm{F}_{0} \mathrm{~F}_{1}$-ATP synthase

\section{The Permeability Transition Pore: Introduction}

Mitochondrial $\mathrm{Ca}^{2+}$ uptake is one of the major mechanisms to lower cytosolic $\mathrm{Ca}^{2+}$ under conditions of $\mathrm{Ca}^{2+}$ overflow in the cytosol. Mitochondria possess $\mathrm{Ca}^{2+}$ channels in the inner membrane (historically called "mitochondrial calcium uniporter") that mediate $\mathrm{Ca}^{2+}$ influx into the organelles driven by high membrane potential across the inner mitochondrial membrane [1-4]. This allows mitochondria to accumulate significant amounts of $\mathrm{Ca}^{2+}$. This large $\mathrm{Ca}^{2+}$ uptake capacity of mitochondria is enabled by the formation of biologically inactive Ca-phosphate precipitates in the mitochondrial matrix [5]. Although mitochondria can accumulate substantial amounts of $\mathrm{Ca}^{2+}$, mitochondrial $\mathrm{Ca}^{2+}$ uptake capacity is finite, and mitochondrial $\mathrm{Ca}^{2+}$ overload comes with a high price. Excessive $\mathrm{Ca}^{2+}$ accumulation by mitochondria can cause mitochondrial damage manifested in the induction of the mitochondrial permeability transition pore (PTP).

Inhibition of the PTP augments $\mathrm{Ca}^{2+}$ accumulation in mitochondria, stabilizes mitochondrial membrane potential, and defers $\mathrm{Ca}^{2+}$ dysregulation. Induction of the PTP, on the other hand, leads to mitochondrial depolarization, inhibition of ATP synthesis and $\mathrm{Ca}^{2+}$ uptake, mitochondrial swelling, and potentially the rupture of the outer mitochondrial membrane. The latter may result in the release of mitochondrial apoptogenic proteins such as cytochrome $c$, Smac/DIABLO, endonuclease G, and AIF. It is not surprising, therefore, that studies of the PTP attract significant attention. Despite significant effort, the exact molecular composition of the PTP is still a matter of hot debate. This review will primarily be focused on the role of the adenine nucleotide translocase (ANT) in the mitochondrial permeability transition. 


\section{Early Studies of the PTP}

Early observations of the PTP manifestations were made in the 1950s and 60s (for review, see Reference [6]). However, the concept of the mitochondrial permeability transition was expressed and introduced by Hunter and Haworth only in the late 1970s [7-10]. In these papers, Hunter and Haworth used the term " $\mathrm{Ca}^{2+}$-induced membrane transition" in mitochondria to signify the large increase in inner membrane permeability and the key role of $\mathrm{Ca}^{2+}$ in triggering this phenomenon [8]. In their seminal work, Hunter and Haworth demonstrated that the $\mathrm{Ca}^{2+}$-induced membrane transition in mitochondria leads to mitochondrial uncoupling, the release of previously accumulated $\mathrm{Ca}^{2+}$, and mitochondrial swelling. The authors described major fundamental properties of the permeability transition, such as the requirement for $\mathrm{Ca}^{2+}$ entry into mitochondria, protection by reduced NADH and mitochondrial energization (membrane polarization), facilitation by membrane depolarization, and inhibition by $\mathrm{H}^{+}, \mathrm{Mg}^{2+}$, and other cations [8,9].

One of the early hypotheses concerning the mechanism of the $\mathrm{Ca}^{2+}$-induced permeability transition postulated that the increase in inner membrane permeability occurs as a result of activation of mitochondrial $\mathrm{Ca}^{2+}$-dependent phospholipase $\mathrm{A}_{2}$ and accumulation of free fatty acids and lysophospholipids that disrupt the phospholipid bilayer [11,12]. However, the discovery that the immunosuppressant cyclosporin A (CsA) suppresses the permeability transition [13,14], but does not inhibit mitochondrial phospholipase $\mathrm{A}_{2}$ [15], suggested that induction/activation of a proteinaceous pore in the inner mitochondrial membrane is most likely responsible for the permeability transition. Since then, the hypothesis that the PTP is a proteinaceous pore has dominated the field. Nevertheless, under conditions of massive $\mathrm{Ca}^{2+}$ accumulation by mitochondria, CsA inhibits PTP only transiently, followed by CsA-insensitive permeability transition, in which activated phospholipase $\mathrm{A}_{2}$ may play an important role [16]. Moreover, palmitate, a free fatty acid that is predominately generated due to phospholipases $\mathrm{A}_{2}$ activity, can induce a CsA-insensitive pore in the inner mitochondrial membrane [17], thereby contributing to $\mathrm{Ca}^{2+}$-induced mitochondrial damage beyond the classic CsA-sensitive PTP.

\section{The Roots of ANT Hypothesis}

In early studies, Hunter and Haworth (1979-80) described ADP's inhibitory effect on the permeability transition, showing that it acted on the matrix side of the inner mitochondrial membrane (IMM). They also demonstrated the opposite effects of atractyloside and bongkrekic acid $[8,18]$, ANT inhibitors that stabilize ANT in $c$ - (nucleotide-binding site facing the cytosol) and $m$ - (nucleotide-binding site facing the mitochondrial matrix) conformational states, respectively [19]. In ADP-depleted mitochondria, atractyloside stimulated, whereas bongkrekic acid antagonized, the permeability transition [8]. This suggested the involvement of ANT in the permeability transition. Consistent with this, an earlier study by Asimakis and Sordahl (1977) showed that atractyloside and an endogenous ANT inhibitor, palmitoyl-coenzyme A, induced the release of previously accumulated $\mathrm{Ca}^{2+}$ from isolated cardiac mitochondria [20], evidently due to induction of the PTP.

Shortly after that, Panov et al. (1980) showed that ADP, in a carboxyatractyloside-sensitive manner, inhibited $\mathrm{H}^{+}$and $\mathrm{K}^{+}$permeability in isolated liver mitochondria [21]. This was interpreted as evidence for ANT being a pathway for passive $\mathrm{H}^{+}$and $\mathrm{K}^{+}$transport across the inner mitochondrial membrane. It has also been speculated that ANT operates as a gated pore [21]. This hypothesis is supported by the ANT's structural model that was proposed soon after and was suggested to operate as a gated pore [22]. Toninello et al. (1983) showed that ADP and ATP protect mitochondria from $\mathrm{Ca}^{2+}$-induced sustained membrane depolarization [23]. Bongkrekic acid also protected against depolarization, whereas atractyloside accelerated it. Interestingly, bongkrekic acid facilitated the protective effect of adenine nucleotides, while atractyloside abolished this protection. The authors agreed with the idea of Panov et al. (1980) that ANT, operating as a gating pore, might be responsible for the $\mathrm{Ca}^{2+}$-induced increase in membrane permeability [23]. Le Quoc and Le Quoc (1988) showed that carboxyatractyloside, palmitoyl coenzyme $\mathrm{A}$, and pyridoxal phosphate, membrane-impermeant inhibitors of ANT, stimulated PTP induction, whereas bongkrekic acid and ADP hindered the 
permeability transition [24]. These authors also provided evidence suggesting that oxidation of sulfhydryl groups linked to oxidation of mitochondrial pyridine nucleotides influenced ANT's conformation, stabilizing it in c-conformation [25]. The latter was linked to the increased probability of the permeability transition.

\section{Mitochondrial Cyclophilin D and Its Interaction with ANT}

In the late 1980s, it was found that CsA binds cyclophilin, a peptidyl-prolyl cis-trans isomerase involved in the folding of different proteins [26,27]. Later, it was shown that mammalian mitochondria have a distinct cyclophilin isoform, cyclophilin D (CyD) [28]. Currently, CyD is the only regulatory component of the PTP considered to be proven. Experiments with CyD-knockout mice showed that genetic ablation of CyD suppresses the permeability transition and increases $\mathrm{Ca}^{2+}$ uptake capacity in mitochondria by two to three-fold [29-32]. Based on these studies, it was postulated that CyD sensitizes the pore to $\mathrm{Ca}^{2+}$ [32]. Importantly, oxidative stress facilitates the recruitment of mitochondrial $\mathrm{CyD}$ to the inner membrane and promotes the permeability transition [33].

Consequently, the effect of CsA on the permeability transition was shown to be mediated by CsA interaction with CyD [34,35]. At the same time, studies of the ANT involvement in induction of the PTP continued. In 1990, Halestrap and Davidson showed that $\mathrm{Ca}^{2+}$-induced swelling of heart mitochondria was inhibited by ADP and bongkrekic acid, and the effect of ADP was reversed by carboxyatractyloside, a more potent derivative of atractyloside [34]. The authors suggested that $\mathrm{Ca}^{2+}$ interacts with ANT when it is in c-conformation and proposed the model in which mitochondrial CyD interacts with ANT in the presence of $\mathrm{Ca}^{2+}$, leading to the permeability transition. Later, Andrew Halestrap's group experimentally proved this hypothesis by demonstrating mitochondrial CyD binding to ANT in the inner mitochondrial membrane and purified ANT [36]. However, these authors failed to find evidence for CyD binding to mitochondrial porin. Later, James Lechleiter's group (2002) also demonstrated the binding of CyD and ANT [37].

In contrast to Halestrap's findings, Martin Crompton's group (1998) reported that CyD binds to a complex of mitochondrial porin (voltage-dependent anion channel, VDAC) and ANT to form the PTP [38]. The authors purified and reconstituted porin, ANT, and the glutathione S-transferase/CyD fusion protein into phosphatidylcholine liposomes loaded with fluorescein. These proteoliposomes were permeabilized by $\mathrm{Ca}^{2+}$ plus $\mathrm{P}_{\mathrm{i}}$, and CsA inhibited this permeabilization. Thus, the authors concluded that the PTP includes porin, ANT, and CyD, and that it is possibly formed at the contact sites between the outer and the inner mitochondrial membranes.

\section{Investigation of ANT as a Pore in Reconstituted Systems}

The findings that ANT inhibitors and ligands can influence the permeability transition suggested ANT involvement in this phenomenon. However, it was not clear whether ANT could only play a modulatory role or whether it could act as the pore. The answer to this question step-by-step came from experiments with reconstituted systems. Reinhard Krämer's group (1990) demonstrated that the aspartate/glutamate carrier and ANT modified by SH-reagents could be converted from an obligate exchange mechanism to a unidirectional transport mode, suggesting channel-like activity of the aspartate/glutamate carrier and ANT [39,40]. Using electrophysiological patch-clamp techniques, this group also demonstrated that a $P_{i}$ carrier from Saccharomyces cerevisiae mitochondria could behave as an ion channel, although with relatively low conductance, ranging from 25 to $40 \mathrm{pS}$ in the presence of $\mathrm{Ca}^{2+}$ and $\mathrm{Mg}^{2+}$ [41].

In experiments with ANT reconstituted into a planar bilayer phospholipid membrane, Vladimir Skulachev's group (1994) detected large ion currents following application of the SH-reagent mersalyl [42]. The channel appeared non-selective with multiple sub-levels of conductance ranging from $200 \mathrm{pS}$ up to $1.5 \mathrm{nS}$. This study demonstrated the long-suspected ability of modified ANT to operate as a pore. However, the possibility of $\mathrm{Ca}^{2+}$-induced transformation of ANT into the pore was not demonstrated in this study. 
The possibility of $\mathrm{Ca}^{2+}$-induced transformation of ANT into the pore has been demonstrated in our studies with purified bovine heart ANT reconstituted into giant proteoliposomes [43]. In these experiments, we discovered a $\mathrm{Ca}^{2+}$-dependent, large non-selective channel with multiple sub-states of conductance ranging from 300 to $600 \mathrm{pS}$ in symmetrical $100 \mathrm{mM} \mathrm{KCl}$. Based on its behavior, the ANT-associated channel could be easily distinguished from the porin channel (VDAC). The ANT channel opening required high $\mathrm{Ca}^{2+}$ that we proposed to bind to cardiolipin molecules, which are tightly associated with the ANT [44]. The ANT channel depended on $\mathrm{pH}$ and closed at $\mathrm{pH} 5.2$. In addition, the ANT channel could be partly inhibited by bongkrekic acid and completely inhibited by a combination of bongkrekic acid and ADP. Carboxyatractyloside, as well as cyclosporin A, were without effect. The latter is not surprising because cyclophilin D was not present in these proteoliposomes. These experiments were based on an early idea that ANT operated as a gated channel [22] and showed that ANT indeed could be converted into a large non-selective channel by exposure to high $\mathrm{Ca}^{2+}$.

In the next study, we reconstituted recombinant ANT from Neurospora crassa into giant proteoliposomes and found a large non-selective channel with multiple conductance sub-levels and an open state conductance of 500-700 pS in symmetrical $100 \mathrm{mM} \mathrm{KCl} \mathrm{[45].} \mathrm{The} \mathrm{ANT} \mathrm{channel} \mathrm{required}$ $\mathrm{Ca}^{2+}$ for activation and could be inhibited by ADP and bongkrekic acid. When purified cyclophilin from Neurospora crassa (a single form of cyclophilin is present in both cytosol and mitochondria [46]) was added, it stabilized the ANT channel in the open state. CsA abolished the effect of cyclophilin. Thus, these experiments filled a critical gap in our previous study by showing the stabilizing effect of cyclophilin on the ANT channel open state and CsA-induced inhibition. Overall, the properties of the ANT channel strongly resembled the PTP. This and other observations regarding ANT involvement in the permeability transition suggested that the ANT could be a key conducting component of the PTP. This notion is supported by ANT's crystal structure [47] that revealed a $30 \AA$ deep and $20 \AA$ wide depression in the carrier molecule. When the ANT is stabilized in the c-conformation by carboxyatractyloside, this depression appeared to be open to the cytosolic side, providing a structural basis for pore formation.

In 1996, Dieter Brdiczka's group reconstituted an ANT-porin-hexokinase (or creatine kinase) complex in a planar bilayer phospholipid membrane and detected a large channel with a conductance of $6 \mathrm{nS}$ [48]. The ANT-porin-kinase complex was also reconstituted into phospholipid liposomes loaded with malate or ATP. $\mathrm{Ca}^{2+}$ induced malate and ATP release, whereas N-methylVal-4-cyclosporin, a derivative of CsA [35], inhibited the release of solutes. Based on these observations, the authors concluded that the ANT-porin-kinase complex constitutes the PTP [48]. Although this study's results, to some extent, resembled our findings [43], there was one significant distinction. The ANT-porin-kinase pore detected in electrophysiological experiments did not require $\mathrm{Ca}^{2+}$ to operate as a pore, suggesting that porin interaction with ANT alters ANT channel behavior (although in metabolite efflux experiments, $\mathrm{Ca}^{2+}$ was necessary to stimulate malate and ATP leakage) [48].

In the subsequent study, Brdiczka's group (1998) showed that only ANT-porin-hexokinase but not ANT-porin-creatine kinase complex could be stimulated by $\mathrm{Ca}^{2+}$ to release malate and ATP from proteoliposomes in an N-methylVal-4-cyclosporin-sensitive manner [49]. The authors also found mitochondrial CyD in the ANT-porin-hexokinase complex that could explain sensitivity to $\mathrm{N}$-methylVal-4-cyclosporin. In the following study, Brdiczka's group (1998) showed that ANT purified from rat heart mitochondria and reconstituted into asolectin/cardiolipin vesicles loaded with ATP and malate allowed release of the trapped compounds in response to increasing concentrations of $\mathrm{Ca}^{2+}$ [50]. This $\mathrm{Ca}^{2+}$-induced solute leakage was not sensitive to $\mathrm{N}$-methylVal-4-cyclosporin, but ADP inhibited the leakage. On the other hand, atractyloside and $\mathrm{HgCl}_{2}$ stimulated the release of solutes from ANT-reconstituted liposomes. These results strongly suggested that ANT itself can adopt a pore-like conformation under conditions known to induce the permeability transition in mitochondria [50]. Soon after these studies, Guido Kroemer's group (2000) reported that consistent with our observations [43], ANT reconstituted in the planar bilayer lipid membrane did not mediate 
ion currents unless $\mathrm{Ca}^{2+}$ or atractyloside are applied [51]. Both $\mathrm{Ca}^{2+}$ and atractyloside stimulated ANT channel activity, reaching in symmetrical $100 \mathrm{mM} \mathrm{KCl}$ conductance of 250 and $30 \mathrm{pS}$, respectively. Taken together, numerous experimental findings obtained in different laboratories with isolated mitochondria and reconstituted systems converged at the conclusion that ANT can be converted into a pore by $\mathrm{Ca}^{2+}$ or other factors promoting the permeability transition, and therefore, modified ANT could be a conducting component of the PTP.

\section{Some Discrepancies in Studies of ANT as a Pore}

Although the ANT hypothesis received significant experimental support from many independent investigators, some studies produced results that seem difficult to reconcile with ANT's key role in the permeability transition pore. In early studies, Hunter and Haworth (1979) found the ADP inhibitory effect on the PTP is mediated by ADP acting at two different binding sites [8]. One of these sites appeared to be high affinity and atractyloside-sensitive, belonging to the ANT, while the other is a low affinity and carboxyatractyloside-insensitive site of unknown molecular identity. Novgorodov et al. (1991-1992) showed that in liver and heart mitochondria, the inhibitory effect of CsA was augmented by low concentrations of ADP in a carboxyatractyloside-sensitive manner [52,53]. In these studies, higher concentrations of ADP in combination with CsA inhibited the pore even in the presence of carboxyatractyloside. Based on these findings, the authors proposed that the pore is probably not formed directly by the ANT, and that another ADP-binding protein with low affinity to ADP could be involved in the pore induction/activation. Gizatullina et al. (2005) also reported that high ADP (2 mM) could inhibit the pore in the presence of carboxyatractyloside [54]. In this study, the authors provided some evidence that the low-affinity regulatory ADP binding site is located on the inner membrane's outer side. Halestrap's group (1997) reported that, in liver mitochondria, the $\mathrm{K}_{\mathrm{i}}$ for the inhibitory effect of ADP in the absence and presence of carboxyatractyloside is $1.9 \pm 0.4 \mu \mathrm{M}$ and $27.2 \pm 5.2 \mu \mathrm{M}$, respectively [55]. The authors speculated that this might reflect the existence of two ADP binding sites, one of high and the other of low affinity on the ANT, of which the former is sensitive and the latter insensitive to carboxyatractyloside. However, carboxyatractyloside-insensitive ADP inhibition of the PTP may occur due to ADP binding to a protein other than the ANT, such as to mitochondrial $\mathrm{Ca}^{2+}$ uniporter, which also interacts with ATP and ADP [56] or due to ADP binding to $\mathrm{F}_{0} \mathrm{~F}_{1}$-ATP synthase, which was recently implicated in PTP induction [57-59].

\section{Genetic Manipulations of ANT Expression and the Role of ANT in PTP}

The use of genetic manipulation techniques offered exciting new opportunities in studies of the molecular composition of the PTP. Genetic ablation of ANT was used as a test for its involvement in PTP formation. Using this approach, Doug Wallace's group (2004) generated mice lacking both ANT1 and ANT2 in liver mitochondria [60]. In a series of well-designed experiments, the authors demonstrated that the equal $\mathrm{Ca}^{2+}$ loads that induced the PTP in mitochondria from wild-type mice could not induce PTP in mitochondria from genetically modified mice, lacking ANT1 and ANT2. This apparently indicated the key role of ANT in PTP induction. However, the authors came to the opposite conclusion since a 3-fold increase in $\mathrm{Ca}^{2+}$ load did cause PTP induction in mitochondria of ANT-deficient mice. Consequently, the authors concluded that ANT does not play an essential role in PTP. By the way, there is a report that skeletal muscle mitochondria lacking ANT require an 8-times larger $\mathrm{Ca}^{2+}$ load to induce the permeability transition [61]. Such greatly increased ANT-deficient mitochondria resistance to $\mathrm{Ca}^{2+}$ hardly be considered evidence for a "non-essential" role of ANT in PTP. Correspondingly, the conclusion about the "non-essential" role of ANT in PTP seems misleading. In our opinion, a significant increase in the amount of $\mathrm{Ca}^{2+}$ required for PTP induction in mitochondria from ANT-deficient mice does not disprove an essential role of ANT in PTP, but rather suggests the existence of additional mechanisms involved in PTP formation. 


\section{Alternative Mechanisms of Conducting Pore Formation in the PTP}

Indeed, over the next ten years, new hypotheses regarding the composition of the PTP have emerged. Andrew Halestrap (2008) proposed that a $P_{i}$ transporter in the inner mitochondrial membrane could be a conducting pathway in the PTP [62]. This is in line with Reinhard Krämer's group's findings that a $P_{i}$ transporter can be converted into a channel-like structure following treatment with mercurials [63]. In another recent study, investigators provided evidence suggesting that the $c$-subunit of the $\mathrm{F}_{0}$ complex in $\mathrm{F}_{0} \mathrm{~F}_{1}$-ATP synthase could be involved in PTP operation [57]. Another remarkable study by Elizabeth Jonas' group provided strong evidence that the $c$-subunit ring of $\mathrm{F}_{0} \mathrm{~F}_{1}$-ATP synthase may constitute the PTP [59]. However, atomistic simulations suggest that the $c$-subunit ring of the $\mathrm{F}_{0} \mathrm{~F}_{1}$-ATP synthase cannot be the PTP [64].

Paolo Bernardi's group proposed an alternative view of the role of $\mathrm{F}_{0} \mathrm{~F}_{1}$-ATP synthase in PTP formation. This group demonstrated that dimers of $\mathrm{F}_{0} \mathrm{~F}_{1}$-ATP synthase could form a large channel in the planar lipid bilayer [58]. This channel was $\mathrm{Ca}^{2+}$-dependent, could be inhibited by ADP and $\mathrm{Mg}^{2+}$, and was insensitive to CsA and ANT inhibitors. To some extent, this channel resembled the "megachannel" described in early studies and attributed to the PTP [65-67]. Further, it was proposed that this PTP-like channel is formed at the membrane interface between two adjacent $\mathrm{F}_{0}$ complexes [6]. Despite significant evidence in favor of the $\mathrm{F}_{0} \mathrm{~F}_{1}$-ATP synthase hypothesis, genetic manipulations with $\mathrm{F}_{0} \mathrm{~F}_{1}$-ATP synthase, which seem to be incompatible with the pore formation, failed to completely prevent PTP induction [68-70].

\section{Reinvigoration of ANT Hypothesis}

Two recent studies renewed the interest in ANT involvement in $\mathrm{Ca}^{2+}$-induced permeability transition and might resolve the existing discrepancies. Karch et al. (2019), using liver mitochondria from Ant1, Ant2, and Ant4 deficient mice and $\mathrm{Ca}^{2+}$ uptake capacity and light scattering assays, demonstrated significant inhibition of PTP induction [71]. Much more $\mathrm{Ca}^{2+}$ was required for induction of the PTP in mitochondria from Ant-triple-knockout mice compared to mitochondria from wild-type animals. Additional deletion of $\mathrm{CyD}$ further increased resistance of mitochondria to PTP induction. In electrophysiological patch-clamp experiments with mouse embryonic fibroblasts (MEF) mitoplasts from Ant-triple-knockout mice, the authors found an almost complete lack of pore-like activity. The rare pores detected in these experiments were insensitive to ADP. The authors proposed that the ANT family is the primary inner-membrane channel-forming component of the MPTP in MEFs and concluded that PTP consists of ANT and an unknown component requiring CyD [71]. These results, however, do not rule out a contribution of other components, such as a mitochondrial Pi carrier or $\mathrm{F}_{0} \mathrm{~F}_{1}$-ATP synthase, to PTP formation.

Evgeny Pavlov's group performed another interesting study. The authors used $\mathrm{F}_{0} \mathrm{~F}_{1}$-ATP synthase $c$-subunit knockout mitochondria from HAP1-A12 cells to investigate the role of the $c$-subunit in the PTP [72]. Using an electrophysiological patch-clamp approach, the authors found that deletion of $c$-subunit eliminates the classic PTP conductance of approximately $1.5 \mathrm{nS}$. Simultaneously, in $c$-subunit knockout cells, the authors detected another channel with conductance around $300 \mathrm{pS}$, which was sensitive to cyclosporin A and bongkrekic acid, an inhibitor of ANT. The authors concluded that while the $c$-subunit of $\mathrm{F}_{0} \mathrm{~F}_{1}$-ATP synthase might be the primary contributor to PTP activity, other proteins, e.g., ANT, could also be involved in $\mathrm{Ca}^{2+}$-induced PTP formation. This may explain why genetic manipulation leading to inactivation or deleting $\mathrm{F}_{0} \mathrm{~F}_{1}$-ATP synthase components may not completely prevent permeability transition [68-70].

Interestingly, mitochondria from $c$-subunit knockout cells more easily undergo permeability transition compared to mitochondria from wild-type cells [72], suggesting that permeability transition linked to the opening of the ANT-associated pore may require less $\mathrm{Ca}^{2+}$, has a higher likelihood of induction, and precede induction of the pore associated with $\mathrm{F}_{0} \mathrm{~F}_{1}$-ATP synthase or other protein/protein complex. This is perfectly consistent with a significantly increased amount of $\mathrm{Ca}^{2+}$ required for PTP induction in mitochondria from Ant1-knockout mice [61], Ant1- and Ant2-double-knockout mice [60], 
and Ant-triple-knockout mice [71]. Overall, identifying a specific protein such as ANT or a protein complex such as $\mathrm{F}_{0} \mathrm{~F}_{1}$ ATP synthase as a "bona fide" PTP is most likely meaningless because different proteins/protein complexes may increase the permeability of the inner mitochondrial membrane. Therefore, the term PTP may comprise different molecular entities involved in the phenomenon of the permeability transition.

\section{Conclusions}

Taken together, none of the existing observations refute a crucial role of ANT in the permeability transition. Moreover, none of these data rule out a pore-forming function of ANT in the PTP. However, the recent data strongly suggest a multiplicity of the mechanisms underlying the permeability transition. This idea is not new and has been introduced by Mario Zoratti and colleagues 15 years ago in their excellent review paper on the PTP [73] and by Martin Klingenberg, a world-renowned expert on ANT, in his excellent review paper on ANT [74]. The "exclusion method", when the investigators genetically delete a certain protein in an attempt to determine its involvement in a specific process, may not be applicable in the case of PTP investigation. Assuming a possible variety of mechanisms and many molecular entities underlying the PTP, removing a single pore-forming molecular component contributing to PTP may not eliminate the whole PTP phenomenon. However, it may rather change some of its properties, such as increasing $\mathrm{Ca}^{2+}$ load or prolonging the time necessary for PTP formation. It seems conceivable that accepting the idea regarding the multiplicity of the permeability transition mechanisms could be a key to answering many questions about structure, function, and the pharmacological profile of the PTP. Consequently, accepting the idea that multiple mechanisms underlie the permeability transition may help to understand the complex nature of this phenomenon better and resolve many controversial issues regarding the molecular identity of the PTP.

Funding: This research was funded by NIH/NINDS grant R01 NS098772.

Conflicts of Interest: The author declares no conflict of interest.

\section{References}

1. Kirichok, Y.; Krapivinsky, G.; Clapham, D.E. The mitochondrial calcium uniporter is a highly selective ion channel. Nat. Cell Biol. 2004, 427, 360-364. [CrossRef]

2. Perocchi, F.; Gohil, V.M.; Girgis, H.S.; Bao, X.R.; McCombs, J.E.; Palmer, A.E.; Mootha, V.K. MICU1 encodes a mitochondrial $\mathrm{EF}$ hand protein required for $\mathrm{Ca}^{2+}$ uptake. Nat. Cell Biol. 2010, 467, 291-296. [CrossRef]

3. De Stefani, D.; Raffaello, A.; Teardo, E.; Szabò, I.; Rizzuto, R. A forty-kilodalton protein of the inner membrane is the mitochondrial calcium uniporter. Nat. Cell Biol. 2011, 476, 336-340. [CrossRef]

4. Baughman, J.M.; Perocchi, F.; Girgis, H.S.; Plovanich, M.; Belcher-Timme, C.A.; Sancak, Y.; Bao, X.R.; Strittmatter, L.; Goldberger, O.; Bogorad, R.L.; et al. Integrative genomics identifies MCU as an essential component of the mitochondrial calcium uniporter. Nat. Cell Biol. 2011, 476, 341-345. [CrossRef]

5. Pivovarova, N.B.; Nguyen, H.V.; Winters, C.A.; Brantner, C.A.; Smith, C.L.; Andrews, S.B. Excitotoxic Calcium Overload in a Subpopulation of Mitochondria Triggers Delayed Death in Hippocampal Neurons. J. Neurosci. 2004, 24, 5611-5622. [CrossRef] [PubMed]

6. Bernardi, P. The mitochondrial permeability transition pore: A mystery solved? Front. Physiol. 2013, 4. [CrossRef] [PubMed]

7. Hunter, D.R.; Haworth, R.; Southard, J.H. Relationship between configuration, function, and permeability in calcium-treated mitochondria. J. Biol. Chem. 1976, 251, 5069-5077. [PubMed]

8. Hunter, D.R.; Haworth, R.A. The $\mathrm{Ca}^{2+}$-induced membrane transition in mitochondria. I. The protective mechanisms. Arch. Biochem. Biophys. 1979, 195, 453-459. [CrossRef]

9. Hunter, D.R.; Haworth, R.A. The $\mathrm{Ca}^{2+}$-induced membrane transition in mitochondria. II. Nature of the $\mathrm{Ca}^{2+}$ trigger site. Arch. Biochem. Biophys. 1979, 195, 460-467. [CrossRef]

10. Hunter, D.R.; Haworth, R.A. The $\mathrm{Ca}^{2+}$-induced membrane transition in mitochondria. III. Transitional $\mathrm{Ca}^{2+}$ release. Arch. Biochem. Biophys. 1979, 195, 468-477. [CrossRef] 
11. Beatrice, M.C.; Palmer, J.W.; Pfeiffer, D.R. The relationship between mitochondrial membrane permeability, membrane potential, and the retention of $\mathrm{Ca}^{2+}$ by mitochondria. J. Biol. Chem. 1980, 255, 8663-8671. [PubMed]

12. Pfeiffer, D.R.; Schmid, P.C.; Beatrice, M.C.; Schmid, H.H. Intramitochondrial phospholipase activity and the effects of $\mathrm{Ca}^{2+}$ plus N-ethylmaleimide on mitochondrial function. J. Biol. Chem. 1979, 254, 11485-11494. [PubMed]

13. Fournier, N.; Ducet, G.; Crevat, A. Action of cyclosporine on mitochondrial calcium fluxes. J. Bioenerg. Biomembr. 1987, 19, 297-303. [CrossRef] [PubMed]

14. Crompton, M.; Ellinger, H.; Costi, A. Inhibition by cyclosporin A of a $\mathrm{Ca}^{2+}$-dependent pore in heart mitochondria activated by inorganic phosphate and oxidative stress. Biochem. J. 1988, 255, 357-360.

15. Broekemeier, K.M.; Dempsey, M.; Pfeiffer, D.R. Cyclosporin A is a potent inhibitor of the inner membrane permeability transition in liver mitochondria. J. Biol. Chem. 1989, 264, 7826-7830.

16. Broekemeier, K.M.; Pfeiffer, U.R. Cyclosporin A-sensitive and insensitive mechanisms produce the permeability transition in mitochondria. Biochem. Biophys. Res. Commun. 1989, 163, 561-566. [CrossRef]

17. Sultan, A.; Sokolove, P.M. Palmitic Acid Opens a Novel Cyclosporin A-Insensitive Pore in the Inner Mitochondrial Membrane. Arch. Biochem. Biophys. 2001, 386, 37-51. [CrossRef]

18. Haworth, R.A.; Hunter, D.R. Allosteric inhibition of the $\mathrm{Ca}^{2+}$-activated hydrophilic channel of the mitochondrial inner membrane by nucleotides. J. Membr. Biol. 1980, 54, 231-236. [CrossRef]

19. Buchanan, B.B.; Eiermann, W.; Riccio, P.; Aquila, H.; Klingenberg, M. Antibody evidence for different conformational states of ADP, ATP translocator protein isolated from mitochondria. Proc. Natl. Acad. Sci. USA 1976, 73, 2280-2284. [CrossRef]

20. Asimakis, G.; Sordahl, L.A. Effects of atractyloside and palmitoyl coenzyme A on calcium transport in cardiac mitochondria. Arch. Biochem. Biophys. 1977, 179, 200-210. [CrossRef]

21. Panov, A.; Filippova, S.; Lyakhovich, V. Adenine nucleotide translocase as a site of regulation by ADP of the rat liver mitochondria permeability to $\mathrm{H}^{+}$and $\mathrm{K}^{+}$ions. Arch. Biochem. Biophys. 1980, 199, 420-426. [CrossRef]

22. Klingenberg, M. Membrane protein oligomeric structure and transport function. Nat. Cell Biol. 1981, 290, 449-454. [CrossRef] [PubMed]

23. Toninello, A.; Siliprandi, D.; Siliprandi, N. On the mechanism by which $\mathrm{Mg}^{2+}$ and adenine nucleotides restore membrane potential in rat liver mitochondria deenergized by $\mathrm{Ca}^{2+}$ and phosphate. Biochem. Biophys. Res. Commun. 1983, 111, 792-797. [CrossRef]

24. Lêquôc, K.; Lêquôc, D. Involvement of the ADPATP carrier in calcium-induced perturbations of the mitochondrial inner membrane permeability: Importance of the orientation of the nucleotide binding site. Arch. Biochem. Biophys. 1988, 265, 249-257. [CrossRef]

25. Le-Quoc, D.; Le-Quoc, K. Relationships between the NAD $(\mathrm{P})$ redox state, fatty acid oxidation, and inner membrane permeability in rat liver mitochondria. Arch. Biochem. Biophys. 1989, 273, 466-478. [CrossRef]

26. Takahashi, N.; Hayano, T.; Suzuki, M. Peptidyl-prolyl cis-trans isomerase is the cyclosporin A-binding protein cyclophilin. Nat. Cell Biol. 1989, 337, 473-475. [CrossRef] [PubMed]

27. Fischer, G.; Wittmann-Liebold, B.; Lang, K.; Kiefhaber, T.; Schmid, F.X. Cyclophilin and peptidyl-prolyl cis-trans isomerase are probably identical proteins. Nat. Cell Biol. 1989, 337, 476-478. [CrossRef]

28. Connern, C.P.; Halestrap, A.P. Purification and N-terminal sequencing of peptidyl-prolyl cis-trans-isomerase from rat liver mitochondrial matrix reveals the existence of a distinct mitochondrial cyclophilin. Biochem. J. 1992, 284, 381-385. [CrossRef]

29. Baines, C.P.; Kaiser, R.A.; Purcell, N.H.; Blair, N.S.; Osinska, H.; Hambleton, M.A.; Brunskill, E.W.; Sayen, M.R.; Gottlieb, R.A.; Ii, G.W.D.; et al. Loss of cyclophilin D reveals a critical role for mitochondrial permeability transition in cell death. Nat. Cell Biol. 2005, 434, 658-662. [CrossRef]

30. Nakagawa, T.; Shimizu, S.; Watanabe, T.; Yamaguchi, O.; Otsu, K.; Yamagata, H.; Inohara, H.; Kubo, T.; Tsujimoto, Y. Cyclophilin D-dependent mitochondrial permeability transition regulates some necrotic but not apoptotic cell death. Nat. Cell Biol. 2005, 434, 652-658. [CrossRef]

31. Schinzel, A.C.; Takeuchi, O.; Huang, Z.; Fisher, J.K.; Zhou, Z.; Rubens, J.; Hetz, C.; Danial, N.N.; Moskowitz, M.A.; Korsmeyer, S.J. Cyclophilin D is a component of mitochondrial permeability transition and mediates neuronal cell death after focal cerebral ischemia. Proc. Natl. Acad. Sci. USA 2005, 102, 12005-12010. [CrossRef] [PubMed]

32. Basso, E.; Fante, L.; Fowlkes, J.; Petronilli, V.; Forte, M.A.; Bernardi, P. Properties of the Permeability Transition Pore in Mitochondria Devoid of Cyclophilin D. J. Biol. Chem. 2005, 280, 18558-18561. [CrossRef] [PubMed] 
33. Connern, C.P.; Halestrap, A.P. Recruitment of mitochondrial cyclophilin to the mitochondrial inner membrane under conditions of oxidative stress that enhance the opening of a calcium-sensitive non-specific channel. Biochem. J. 1994, 302, 321-324. [CrossRef] [PubMed]

34. Halestrap, A.P.; Davidson, A.M. Inhibition of $\mathrm{Ca}^{2+}$-induced large-amplitude swelling of liver and heart mitochondria by cyclosporin is probably caused by the inhibitor binding to mitochondrial-matrix peptidyl-prolyl cis-trans isomerase and preventing it interacting with the adenine nucleotide translocase. Biochem. J. 1990, 268, 153-160. [CrossRef]

35. Nicolli, A.; Basso, E.; Petronilli, V.; Wenger, R.M.; Bernardi, P. Interactions of Cyclophilin with the Mitochondrial Inner Membrane and Regulation of the Permeability Transition Pore, a Cyclosporin A-sensitive Channel. J. Biol. Chem. 1996, 271, 2185-2192. [CrossRef]

36. Woodfield, K.; Rück, A.; Brdiczka, D.; Halestrap, A.P. Direct demonstration of a specific interaction between cyclophilin-D and the adenine nucleotide translocase confirms their role in the mitochondrial permeability transition. Biochem. J. 1998, 336, 287-290. [CrossRef]

37. Lin, D.-T.; Lechleiter, J.D. Mitochondrial Targeted Cyclophilin D Protects Cells from Cell Death by Peptidyl Prolyl Isomerization. J. Biol. Chem. 2002, 277, 31134-31141. [CrossRef]

38. Crompton, M.; Virji, S.; Ward, J.M. Cyclophilin-D binds strongly to complexes of the voltage-dependent anion channel and the adenine nucleotide translocase to form the permeability transition pore. JBIC J. Biol. Inorg. Chem. 1998, 258, 729-735. [CrossRef]

39. Dierks, T.; Salentin, A.; Heberger, C.; Krämer, R. The mitochondrial aspartate/glutamate and ADP/ATP carrier switch from obligate counterexchange to unidirectional transport after modification by SH-reagents. Biochim. Biophys. Acta (BBA) Biomembr. 1990, 1028, 268-280. [CrossRef]

40. Dierks, T.; Salentin, A.; Kramer, R. Pore-like and carrier-like properties of the mitochondrial aspartate/glutamate carrier after modification by SH-reagents: Evidence for a performed channel as a structural requirement of carrier-mediated transport. Biochim. Biophys. Acta 1990, 1028, 281-288. [CrossRef]

41. Herick, K.; Krämer, R.; Lühring, H. Patch clamp investigation into the phosphate carrier from Saccharomyces cerevisiae mitochondria. Biochim. Biophys. Acta (BBA) Bioenerg. 1997, 1321, 207-220. [CrossRef]

42. Tikhonova, I.; Kaulen, A.; Skulachev, V.; Andreyev, A.Y.; Antonenko, Y.; Komrakov, A. Ion permeability induced in artificial membranes by the ATP/ADP antiporter. FEBS Lett. 1994, 337, 231-234. [CrossRef]

43. Brustovetsky, N.; Klingenberg, M. Mitochondrial ADP/ATP Carrier Can Be Reversibly Converted into a Large Channel by $\mathrm{Ca}^{2+}$. Biochemistry 1996, 35, 8483-8488. [CrossRef] [PubMed]

44. Beyer, K.; Klingenberg, M. ADP/ATP carrier protein from beef heart mitochondria has high amounts of tightly bound cardiolipin, as revealed by 31P nuclear magnetic resonance. Biochemistry 1985, 24, 3821-3826. [CrossRef] [PubMed]

45. Brustovetsky, N.; Tropschug, M.; Heimpel, S.; Heidkämper, D.; Klingenberg, M. A Large Ca ${ }^{2+}$-Dependent Channel Formed by Recombinant ADP/ATP Carrier from Neurospora crassa Resembles the Mitochondrial Permeability Transition Pore. Biochemistry 2002, 41, 11804-11811. [CrossRef] [PubMed]

46. Tropschug, M.; Nicholson, D.W.; Hartl, F.U.; Köhler, H.; Pfanner, N.; Wachter, E.; Neupert, W. Cyclosporin A-binding protein (cyclophilin) of Neurospora crassa. One gene codes for both the cytosolic and mitochondrial forms. J. Biol. Chem. 1988, 263, 14433-14440.

47. Pebay-Peyroula, E.; Dahout-Gonzalez, C.; Kahn, R.; Trézéguet, V.; Lauquin, G.J.-M.; Brandolin, G. Structure of mitochondrial ADP/ATP carrier in complex with carboxyatractyloside. Nat. Cell Biol. 2003, 426, 39-44. [CrossRef]

48. Beutner, G.; Rück, A.; Riede, B.; Welte, W.; Brdiczka, D. Complexes between kinases, mitochondrial porin and adenylate translocator in rat brain resemble the permeability transition pore. FEBS Lett. 1996, 396, 189-195. [CrossRef]

49. Beutner, G.; Rück, A.; Riede, B.; Brdiczka, D. Complexes between porin, hexokinase, mitochondrial creatine kinase and adenylate translocator display properties of the permeability transition pore. Implication for regulation of permeability transition by the kinases. Biochim. Biophys. Acta (BBA) Biomembr. 1998, 1368, 7-18. [CrossRef]

50. Rück, A.; Dolder, M.; Wallimann, T.; Brdiczka, D. Reconstituted adenine nucleotide translocase forms a channel for small molecules comparable to the mitochondrial permeability transition pore. FEBS Lett. 1998, 426, 97-101. [CrossRef]

51. Brenner, C.; Cadiou, H.; Vieira, H.L.A.; Zamzami, N.; Marzo, I.; Xie, Z.; Leber, B.; Andrews, D.W.; Duclohier, H.; Reed, J.C.; et al. Bcl-2 and Bax regulate the channel activity of the mitochondrial adenine nucleotide translocator. Oncogene 2000, 19, 329-336. [CrossRef] [PubMed] 
52. Novgorodov, S.A.; Gudz, T.I.; Jung, D.W.; Brierley, G.P. The nonspecific inner membrane pore of liver mitochondria: Modulation of cyclosporin sensitivity by ADP at carboxyatractyloside-sensitive and insensitive sites. Biochem. Biophys. Res. Commun. 1991, 180, 33-38. [CrossRef]

53. Novgorodov, S.; Gudz, T.; Milgrom, Y.M.; Brierley, G.P. The permeability transition in heart mitochondria is regulated synergistically by ADP and cyclosporin A. J. Biol. Chem. 1992, 267, 16274-16282.

54. Gizatullina, Z.Z.; Chen, Y.; Zierz, S.; Gellerich, F.N. Effects of extramitochondrial ADP on permeability transition of mouse liver mitochondria. Biochim. Biophys. Acta (BBA) Gen. Subj. 2005, 1706, 98-104. [CrossRef] [PubMed]

55. Halestrap, A.P.; Woodfield, K.-Y.; Connern, C.P. Oxidative Stress, Thiol Reagents, and Membrane Potential Modulate the Mitochondrial Permeability Transition by Affecting Nucleotide Binding to the Adenine Nucleotide Translocase. J. Biol. Chem. 1997, 272, 3346-3354. [CrossRef]

56. Litsky, M.L.; Pfeiffer, D.R. Regulation of the Mitochondrial $\mathrm{Ca}^{2+}$ Uniporter by External Adenine Nucleotides: The Uniporter Behaves Like a Gated Channel Which Is Regulated by Nucleotides and Divalent Cations. Biochemistry 1997, 36, 7071-7080. [CrossRef]

57. Bonora, M.; Bononi, A.; De, M.E.; Giorgi, C.; Lebiedzinska, M.; Marchi, S.; Patergnani, S.; Rimessi, A.; Suski, J.M.; Wojtala, A.; et al. Role of the c subunit of the FO ATP synthase in mitochondrial permeability transition. Cell Cycle 2013, 12, 674-683. [CrossRef]

58. Giorgio, V.; Von Stockum, S.; Antoniel, M.; Fabbro, A.; Fogolari, F.; Forte, M.; Glick, G.D.; Petronilli, V.; Zoratti, M.; Szabó, I.; et al. Dimers of mitochondrial ATP synthase form the permeability transition pore. Proc. Natl. Acad. Sci. USA 2013, 110, 5887-5892. [CrossRef]

59. Alavian, K.N.; Beutner, G.; Lazrove, E.; Sacchetti, S.; Park, H.-A.; Licznerski, P.; Li, H.; Nabili, P.; Hockensmith, K.; Graham, M.; et al. An uncoupling channel within the c-subunit ring of the F1FO ATP synthase is the mitochondrial permeability transition pore. Proc. Natl. Acad. Sci. USA 2014, 111, 10580-10585. [CrossRef]

60. Kokoszka, J.E.; Waymire, K.G.; Levy, S.E.; Sligh, J.E.; Cai, J.; Jones, D.P.; MacGregor, G.R.; Wallace, D.C. The ADP/ATP translocator is not essential for the mitochondrial permeability transition pore. Nat. Cell Biol. 2004, 427, 461-465. [CrossRef]

61. Panov, A.V.; Andreeva, L.; Greenamyre, J. Quantitative evaluation of the effects of mitochondrial permeability transition pore modifiers on accumulation of calcium phosphate: Comparison of rat liver and brain mitochondria. Arch. Biochem. Biophys. 2004, 424, 44-52. [CrossRef] [PubMed]

62. Leung, A.W.C.; Varanyuwatana, P.; Halestrap, A.P. The Mitochondrial Phosphate Carrier Interacts with Cyclophilin D and May Play a Key Role in the Permeability Transition. J. Biol. Chem. 2008, 283, 26312-26323. [CrossRef] [PubMed]

63. Schroers, A.; Krämer, R.; Wohlrab, H. The Reversible Antiport-Uniport Conversion of the Phosphate Carrier from Yeast Mitochondria Depends on the Presence of a Single Cysteine. J. Biol. Chem. 1997, 272, 10558-10564. [CrossRef] [PubMed]

64. Zhou, W.; Marinelli, F.; Nief, C.; Faraldo-Gómez, J.D. Atomistic simulations indicate the c-subunit ring of the F1Fo ATP synthase is not the mitochondrial permeability transition pore. eLife 2017, 6, 10580. [CrossRef]

65. Petronilli, V.; Szabò, I.; Zoratti, M. The inner mitochondrial membrane contains ion-conducting channels similar to those found in bacteria. FEBS Lett. 1989, 259, 137-143. [CrossRef]

66. Szabó, I.; Zoratti, M. The giant channel of the inner mitochondrial membrane is inhibited by cyclosporin A. J. Biol. Chem. 1991, 266, 3376-3379.

67. Szabó, I.; Bernardi, P.; Zoratti, M. Modulation of the mitochondrial megachannel by divalent cations and protons. J. Biol. Chem. 1992, 267, 2940-2946.

68. He, J.; Ford, H.C.; Carroll, J.; Ding, S.; Fearnley, I.M.; Walker, J.E. Persistence of the mitochondrial permeability transition in the absence of subunit c of human ATP synthase. Proc. Natl. Acad. Sci. USA 2017, 114, 3409-3414. [CrossRef]

69. He, J.; Carroll, J.; Ding, S.; Fearnley, I.M.; Walker, J.E. Permeability transition in human mitochondria persists in the absence of peripheral stalk subunits of ATP synthase. Proc. Natl. Acad. Sci. USA 2017, 114, 9086-9091. [CrossRef]

70. Carroll, J.; He, J.; Ding, S.; Fearnley, I.M.; Walker, J.E. Persistence of the permeability transition pore in human mitochondria devoid of an assembled ATP synthase. Proc. Natl. Acad. Sci. USA 2019, 116, 12816-12821. [CrossRef] 
71. Karch, J.M.; Bround, M.J.; Khalil, H.; Sargent, M.A.; Latchman, N.; Terada, N.; Peixoto, P.M.; Molkentin, J.D. Inhibition of mitochondrial permeability transition by deletion of the ANT family and CypD. Sci. Adv. 2019, 5, eaaw4597. [CrossRef] [PubMed]

72. Neginskaya, M.A.; Solesio, M.E.; Berezhnaya, E.V.; Amodeo, G.F.; Mnatsakanyan, N.; Jonas, E.A.; Pavlov, E.V. ATP Synthase C-Subunit-Deficient Mitochondria Have a Small Cyclosporine A-Sensitive Channel, but Lack the Permeability Transition Pore. Cell Rep. 2019, 26, 11-17. [CrossRef] [PubMed]

73. Zoratti, M.; Szabò, I.; De Marchi, U. Mitochondrial permeability transitions: How many doors to the house? Biochim. Biophys. Acta (BBA) Bioenerg. 2005, 1706, 40-52. [CrossRef] [PubMed]

74. Klingenberg, M. The ADP and ATP transport in mitochondria and its carrier. Biochim. Biophys. Acta (BBA) Biomembr. 2008, 1778, 1978-2021. [CrossRef] [PubMed]

Publisher's Note: MDPI stays neutral with regard to jurisdictional claims in published maps and institutional affiliations.

(C) 2020 by the author. Licensee MDPI, Basel, Switzerland. This article is an open access article distributed under the terms and conditions of the Creative Commons Attribution (CC BY) license (http://creativecommons.org/licenses/by/4.0/). 